\begin{abstract}
Haryadi Arief Nuur Rasyid ${ }^{1}$, Zuhdan
Azis $^{2}$

1Prodi IImu K omunikasi, Fisipol,

U niversitas M uhammadiyah Yogyakarta

2Prodi IImu K omunikasi, Fisipol,

U niversitas M uhammadiyah Yogyakarta

Jalan Brawijaya, Tamantirto, K asihan,

Bantul, Yogyakarta 55183

'E mail:

haryadiariefnuurrasyid@yahoo.co.id
\end{abstract}

https:/ / doi.org/ 10.18196/ bdr.5115

\begin{abstract}
Nowdays, snack products have new creations with started to be widely available. However, it is produced by micro, small and medium enterprises (UMKM), of course also experience constraints as MSME in general is not professional yet did by the people and can not produce continuously. It is a small business, the production aspect of UMKM also uses simple methods and technology and still uses simple management as well. SMEs that move in the fulfillment of culinary tourism also has constraints and has characteristics sebagaiman above. Culinary business that seeks to support tourism include eel products/fried catfish crispy and seaweed. Both of these efforts are done by young people who are creative and have a willingness to go forward developing the business. For catfish fried crispy is done by Noviani brass with trademark "Sari Rasa" while for various snack that comes from seaweed developed by Br. Stenley Avanda with brand "Panda". Once identified through observation and interviews it can be seen that the problems that are still faced include: 1) not understood yet how to market products to foreign tourists, 2) not to implementation yet of professional governance and administration, including the absence of a good business plan, and regular organizational systems; 3) unavailability of English-speaking product packaging; 4) lack of promotion media using the internet; 5 ) the need for more intensive management assistance to penetrate the wider market. From these problems, efforts have been made to overcome them through activities such as the understanding of export management or foreign tourism through applicative training, product promotion by using English packaging, making brochures with english language and making english-language website. From a series of activities, both partners benefit from increased understanding of product sales to foreign tourists, and can take advantage of promotional media in accordance with the needs of foreign tourists.
\end{abstract}

Keywords: Governance, promotion, various snacks.

\title{
PENDAHULUAN
}

Seiring dengan perkembangan pariwisata di negeri ini usaha kuliner bagi U M KM sekarang ini juga men galami peningkatan. Masyarakat yang melakukan perjalanan wisata sebagain besar juga melakukan belanja oleh-oleh di tempat dimana mereka kunjungi. Aneka snack yang merupakan oleh-oleh khas dari lokasi wisata yang dikunjungi akan mempunyai daya tarik tersendiri bagi wisatawan baik domestik maupun mancanegara untuk melakukan perjalanan wisata ke lokasi tersebut. 
Daerah Istimewa Yogyakarta (DIY) merupakan daerah kunjungan wisata yang potensial setelah Bali. M akanan yang merupakan ciri khas Yogyakarta seperti gudeg, bakpia, geplak dan sebagainya sudah menjadi daya tarik tersen diri bagi wisatawan. Namun tentu saja perlu dikembangkan produk-produk lain yang bisa bersanding dengan makanan -makanan khas tersebut agar wisatawan juga mempunyai banyak pilihan dan tidak bosan. $\mathrm{H}$ al ini memungkinkan karena wisatawan sebagaimana yang dikemukakan oleh Pitana (2009) selalu akan mencari sensasi yang baru, baik berupa petualangan maupun makanan yang menjadi ciri khas dari daerah yang dikunjungi.

Pada akhir-akhir ini sudah mulai terpikirkan baik oleh pemerintah maupun masyarakat untuk men gembangkan makanan lain yang bisa dijadikan alternatif bagi wisatawan apabila berkunjung keYogyakarta. $\mathrm{H}$ al ini sudah mulai terealisir dengan adanya produk makanan kecil (snack) seperti belut goreng, lele goreng crispy, dan rumput laut. A sal mula dikembangkan makanan atau oleh-oleh alternatif ini memang berdekatan sekali dengan idustri kreatif, karena memang pengembangan pariwisata juga berbarengan dengan pengembangan industri kreatif, yaitu kreatif untuk selalu membuat inovasi dalam memberikan pelayanan dan penyediaan wisata kuliner.

Selama ini produk makanan kecil yang merupakan kreasi baru tersebut sudah mulai banyak tersedia namun karena diproduksi oleh U M KM tentu sajajuga men galami kendala sebagaimana U M KM pada umumnya, yaitu belum profesional, dikerjakan ala rakyat, dan belum bisa produksi secara kontinyu. Karena merupakan bisnis kecil maka aspek produksi dari U M KM ini juga menggunakan metode dan teknologi yang sederhana dan masih menggunakan manajemen yang sederhana pula.

D ari aspek produksi biasanya menggunakan rumah sendiri sebagai tempat usahanya dan dari segi manajemen tidak ada perencanaan dan kontrol kualitas serta belum ada pemisahan antara aset untuk usaha den gan kekayaan pribadi. M ereka dalam menawarkan produknya sebagian besar juga masih dalam kemasan yang belum bisa dipahami oleh wisatawan mancanegara.

Keterbatasan sumberdaya yang dimiliki merupakan persoalan utama dari U M KM . Persoalan utama dari UM KM tersebut terutama yang mikro kecil tidak mempunyai sumberdaya yang berlebih, baik dari segi permodalan, kapasitas produksi, manajemen usaha maupun pemasaran produk (Susanta, 2009). A gar usaha yang tergolong mikro ini dapat berkembang maka perlu adanya dorongan dan fasilitasi agar bisa maju dan berlanjut. 


\section{PERMASALAHAN MITRA}

U M KM yang bergerak dalam pemenuhan wisata kuliner juga mengalami kendala dan mempunyai karakteristik sebagaiman tersebut diatas. U saha kuliner yang berusaha untuk menunjang pariwisata tersebut antara lain adalah produk belut/ lele goreng crispy dan rumput laut. Kedua usaha ini dilakukan oleh anak muda yang kreatif dan mempunyai kemauan untuk maju mengembangkan usaha. U ntuk produk belut/ lele goreng crispy dilakukan oleh sdr Noviani dengan merek dagang "Sari Rasa" sedangkan untuk aneka snack yang berasal dari rumput laut dikembangkan oleh sdr Stenley Avanda dengan merek "Panda".

Dari segi aspek produksi kedua usaha tersebut masih terbatas karena hanya untuk memenuhi kebutuhan wisatawan di DIY saja dan masih terbatas pada wisatawan domestik. Padahal kalau dilihat dari potensinya, wisatawan mancanegara juga bisa dibibik menjadi pasar yang prospektif dari aneka snack tersebut. D an dari hasil wawancara dengan kedua pengusaha muda tersebut mereka mempunyai antusiasme yang tinggi untuk juga mencoba menawarkan pada wisatawan mancanegara. M alah tidak tertutup kemungkinan untuk memasarkan sampai keluar negeri (ekspor).

Manajemen usaha khususnya mengenai tata kelola dan pemasaran masih bersifat tradisional, mereka masih menggunakan sistem administrasi perusahaan yang bersifat manual dan belum mempunyai media promosi yanginteraktif dan berbasiswebsite. Belum ada perencanaan produk dan pemasaran yang sistematis dan berlanjut, semua dilakukan sekedar by order tidak didasarkan pada perencanaan bisnis yang mendalam. Bisnis yang dilakukan tentu saja akan mengalami stagnan apabila ada perubahan besar baik dalam kebijakan pemerintah maupun perilaku konsumen.

$\mathrm{H}$ ingga sekarangini kedua pengusaha muda tersebut dalam menjual produknya dengan kemasan yang cukup baik. U ntuk produk belut/ lele goreng crispy dikemas dengan ukuran $200 \mathrm{gr}$ sedangkan snack rumput laut dikemas dengan ukuran $20 \mathrm{gr}$. D ari kedua kemasan tersebut dapat diketahui bahwa semua produk tersebut belum bisa ditawarkan pada wisatawan mancanegara karena masih menggunakan bahasa Indonesia. Perlu dibuat kemasan yang memang bisa diketahui oleh wisatawan mancanegara dengan menggunakan bahasa Inggris.

Dengan melihat kemasan dan juga hasil observasi pada pengusaha tersebut maka dapat diidentifikasi beberapa permasalahan dalam rangka untuk meningkatkan tata kelola dan juga aspek pemasarannya, yaitu :

1. Belum dipahaminya bagaimana memasarkan produk keluar negeri (ekspor). 


\section{5}

2. Belum diterapkannya tata kelola dan administrasi yang bersifat profesional, antara lain belum adanya business plan yang baik, pembagian kerja dan sistem organisasi yang teratur.

3. Belum tersedianya kemasan produk yang berbahasa Inggris.

4. Belum adanya media promosi dengan menggunakan internet.

5. Perlunya pendampingan manajemen yang lebih intensif untuk dapat menembus pasar yang lebih luas.

\section{METODE PELAKSANAAN}

D al am rangka untuk men gatasi persoalan tersebut perlu dicarikan solusi yang aplikatif sehingga kendala yang dihadapi pengusaha tersebut bisa terselesaikan. U paya untuk menyelesaikan persoalan tersebut telah disepakati bersama pihak mitra yakni Noviani dan Stenley Avanda melalui pelatihan dan pendampingan manajemen.

\section{HASIL DAN PEMBAHASAN}

Pelaksanaan kegiatan pengabdian kepada masyarakat ini memperoleh hasil sesuai dengan yang diharapkan. D ari hasil pra-survey dan diskusi yang mendalam maka program yang disepakati meliputi pemahaman terhadap manajemen ekspor, penyusunan perencanaan bisnis (business plan) dan tatakelola, penyempurnaan kemasan dengan bahasa Inggris, promosi dengan menggunakan website, dan pendampingan manajemen.

\section{Pelatihan Manajemen Ekspor}

A gar usaha snack tersebut dapat dipasarkan tidak hanya di dalam negeri maka perlu adanya pemahaman yang komprehensif dari pembuat snack tersebut terhadap manajemen ekspor. Sebagai rintisan atau inisiasi untuk mengarah pada produk yang dapat diterima tidak hanya wisatawan domestik, maka diperlukan pemahaman yang nantinya akan ditindaklanjuti untuk mempersiapkan produk ekspor.

Kegiatan yang bisa dilakukan adalah dengan diberikannya bekal pada pengelola atau pemilik untuk mengetahui bagaimana melakukan prosedur dan mekanisme untuk memenuhi pasar ekspor. Disamping itu juga aspek legalitas apa yang harus dipenuhi untuk dapat menjadi pengekspor. Kegiatan ini dilakukan melalui pelatihan manajemen ekspor yang tidak hanya diikuti oleh kedua mitra tersebut, tetapi juga diperluas pada komunitas aneka snack yang lain. G ambar pelatihan tersebut tampak berikut ini: 

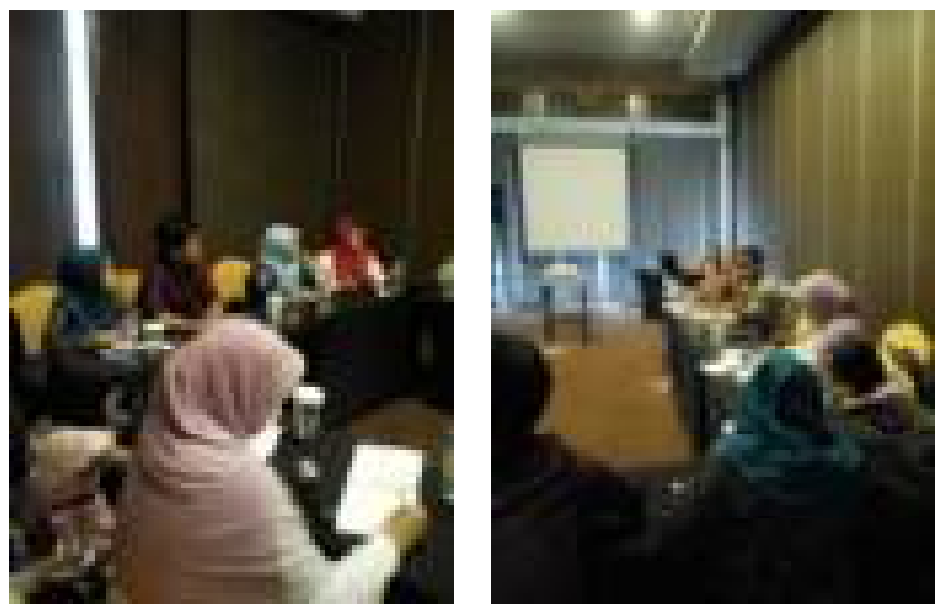

Gambar 1. Dokumentasi Kegiatan Pelatiham Manajemen Ekspor

\section{Kemasan Produk Berbahasa Inggris}

M engingat bahwa produk snack akan dipasarkan kepada wisatawan mancanegara maka agar produk dapat dimengerti dan kepahami oleh wisatawan mancanegara tersebut maka perlu dibuat kemasan dengan menggunakan bahasa Inggris. Gambar dari kemasan berbahasa Inggris dari kedua produk adalah sebagai berikut:

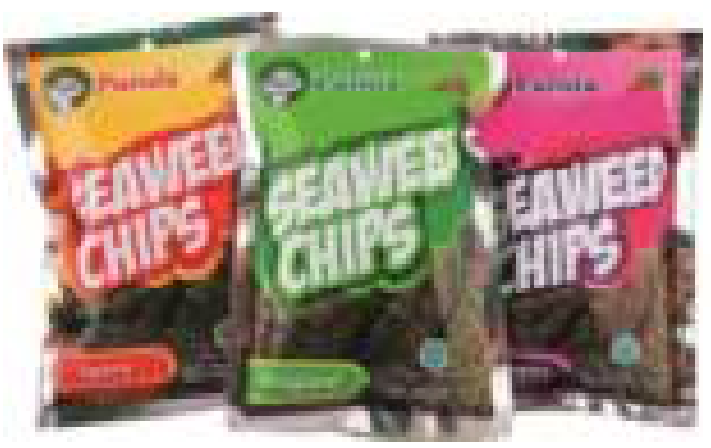

Gambar 2. Kemasan Panda Seaweed Chips

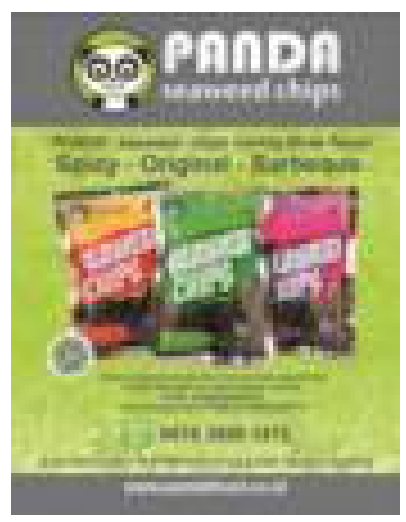

Gambar 4. Brosur Produk "Panda Seaweed Chips"

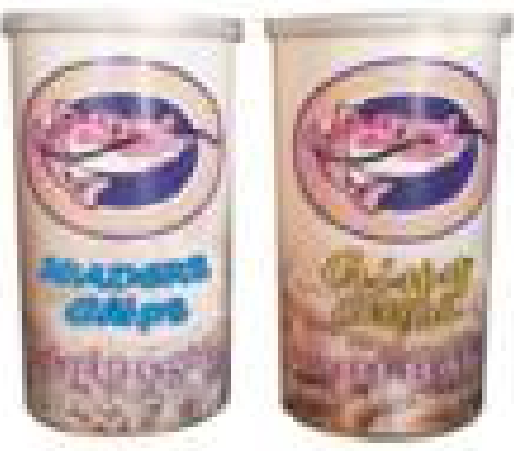

Gambar 3. Kemasan Sari Rasa

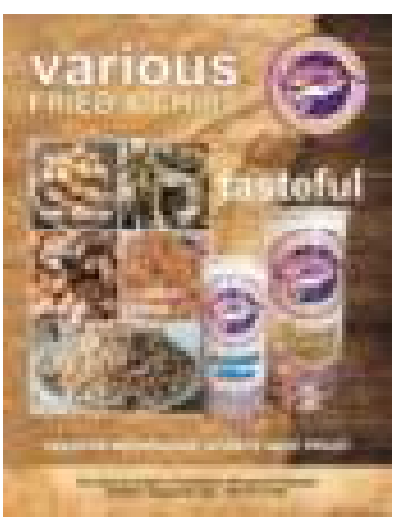

Gambar 5. Brosur Produk Crispy Lele"Sari Rasa" 


\section{Brosur Berbahasa Inggris}

U ntuk lebih mengenalkan produk kepada wisatawan mancanegara diperlukan adanya brosur yang berisi tentang rincian produk. Brosur kedua produk snack bisa dilihat pada gambar 4.

\section{Penyusunan Bisnis Plan dan Tata Kelola}

Bagi para pengusaha muda ini penyusunan bisnis plan merupakan hal baru karena selama ini dalam melakukan usahan tidak didasari oleh pemikiran jangka panjang tetapi hanya sekedar memenuhi pesanan dan berorientasi jangka pendek. Bisnis tidak ubahnya seperti penjualan suatu barang untuk pemenuhan kebutuhan masyarakat untuk mencari keuntungan semata.

D engan adanya bisnis plan suatu usaha akan lebih terarah dan mempunyai sasaran yang nyata untuk mencapai tujuan yang diinginkan. Bisnis plan merupakan rancangan penyelenggaraan sebuah usaha bisnis secara menyeluruh terhadap semua aspek yang dibutuhkan dalam menjalankan sebuah usaha bisnis. M elaui sebuah business plan yang mantap akan memberi jaminan yang lebih keseriusan dari pengelola bisnis yang bersangkutan. Bisnis plan juga merupakan cara untuk meyakinkan pihak investor atau pemberi dana hibah di perusahaan yang kita kelola.

Bisnis plan yang baik akan mengandung isian yang jelas dan mudah dipahami apa sebenarnya yang menjadi maksud tujuan, upaya-upaya, gambaran target, strategi dan sebagainya. Biasanya pihak-pihak pemberi dana hibah akan menilai tak hanya dari aspek kejelasan saja, namun sejauh mana kebermanfaatan dari rancangan bisnis yang diupayakan. Langkah-langkah dan target seperti apa yang dipersiapkan dikemudian hari untuk mengantisipasi berbagai persoalan yang akan dihadapi perusahaan. Dalam keperluan untuk kedua pengusaha muda tersebut maka dengan disusunnya bisnis plan akan memberikan peluang lebih besar untuk memperoleh dana hibah untuk skema ipteks bagi produk ekspor (I bPE) dari DP2M Dikti.

D isamping adanya bisn is plan tersebut, sebuah usaha akan bisa berkembang apabila mempunyai tata kelola yang baik. Pengembangan tata kelola ini bisa dimulai dari dibuatnya struktur organisasi yang memberikan peluang untuk responsif terhadap perubahan dan tantangan. Penyusunan struktur organisasi ini diaplikasikan dengan melalui job deskripsi dari setiap unit yang dibentuk. Sehingga untuk program tata kelola ini bisa dimulai dari penyusunan struktur organisasi, kemudian penyusunan job deskripsi, dan diakhiri dengan membuat standar operasional prosedur (SOP) untuk menunjang dari setiap kegiatan 
baik di sektor produksi maupun pemasaran.

Berikut dokumentasi pada waktu dilakukan pendampingan manjemen dan penyusunan bisnis plan di jurusan IImu Komunikasi U MY:

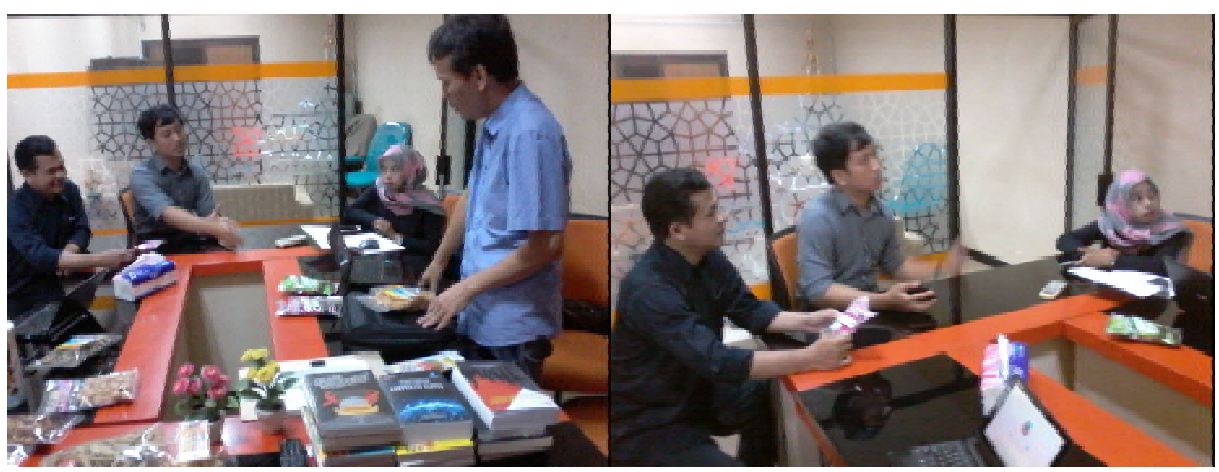

Gambar 6. Diskusi Tata Kelola

\section{Pembuatan Website}

Kegiatan pembuatan website ini dilakukan secara interaktif mulai dari pengumpulan materi, layout desain hingga sampai pada update data. Pembuatan website dilakukan dengan dibantu oleh mahasiswa Jurusan IImu Komunikasi dilaksanakan di laboratorium IImu Komunikasi. Hasil dari diskusi dan pendampingan penyusunan website tersebut adalah sebagai berikut:

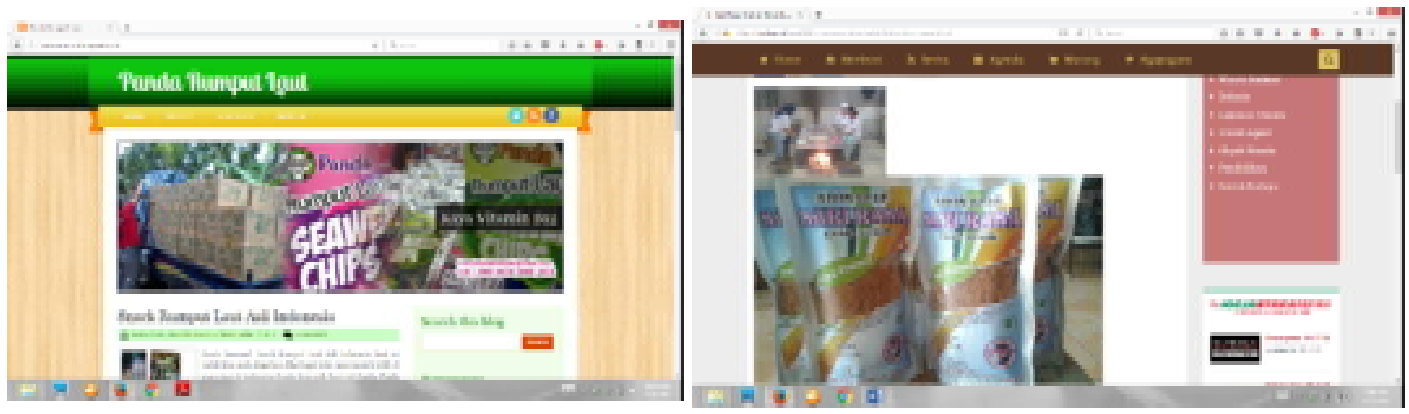

Gambar 7. Website Mitra

\section{Pendampingan Manajemen Pemasaran}

Setelah memperoleh pemahaman tentang manajemen ekspor dan dapat menyusun bisnis plan serta melakukan promosi berbasis website, untuk keberlanjutan dari program ini perlu adanya pendampingan manajemen hingga sampai selesainya program ini. Pemasaran merupakan kegiatan manusia yang diarahkan untuk memenuhi kebutuhan dan keinginan melalui proses pertukaran. Pendampingan manajemen pemasaran

Selain itu juga pendampingan manajemen pemasaran melalui internet marketing, 
mengingat saat ini trend belanja melalui online sudah sedemikian besarnya, sehingga usaha makanan belut/ lele goreng crispy dan rumput laut ini bisa juga dikenal dan mendapatkan pelanggan melalui online. D isamping itu juga agar dapat menembus pasar internasional atau di tempat-tempat yang terdapat banya komunitas turis-turis mancanegara, seperti prambanan, borobudur dan juga hotel-hotel yang banyak wisatawan asing. Suasana pendampingan tampak pada gambar berikut:

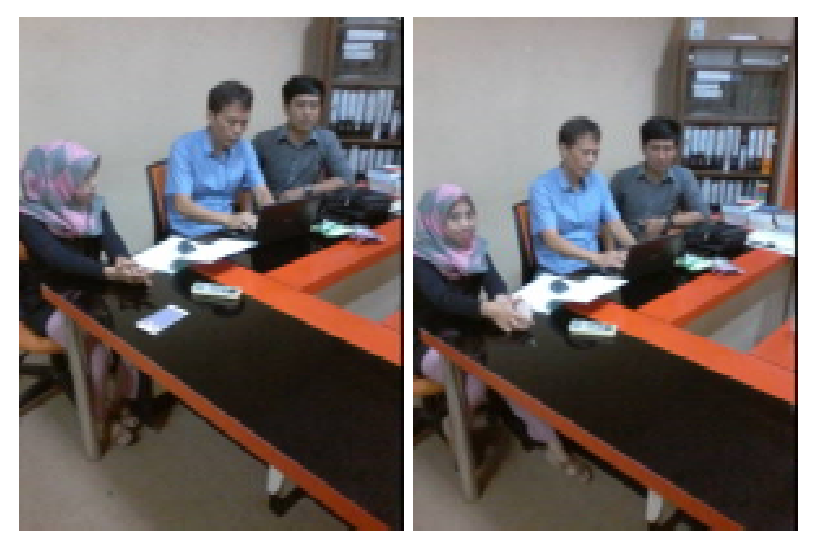

Program pengabdian kepada masyarakat ini dilakukan dengan metode pelatihan dan pendampinan manajemen. Pelatihan dengan mengambil topik manajemen ekspor, memberikan bekal kepada mitra untuk memahami tentang persyaratan dan ketentuan untuk melakukan ekspor. A pa yang harus dilakukan dan persyaratan apa yang harus dipenuhi, menjadi pembahasan yang serius dalam pelatihan tersebut. D ari hasil pelatihan tersebut kedua mitra dan komunitas kuliner memahami langkah konkrit yang harus ditempuh untuk memasarkan produk ke mancanegara.

Dari pelatihan tersebut dilanjutkan dengan pendampingan yang berkaitan dengan media promosi yang memungkinkan untuk dipahami oleh wisatawan mancanegara. Penggunaan media promosi berbahasa Inggris menjadi program utama dalam kegiatan pengabdian masyarakat ini. Dengan didapatkannya brosur, kemasan dan website berbahasa Inggris semakin mudah untuk menawarkan produk kepada wisatawan mancanegara. D engan melalui proses pendampingan yang intensif kedua mitra mampu untuk melakukan inisiasi membuat media promosi yan gramah wisatawan mancanegara.

Seluruh rangkaian kegiatan pengabdian masyarakat ini dilakukan secara simultan dan berurutan maka semua output yang direncanakan dapat dicapai. D ari berbagi output tersebut membawa manfaat bagi kedua mitra untuk melakukan pen gembangan usaha lebih lanjut. Produk rumput laut dengan merek dagang "Panda" sudah mampu masuk 
dalam jaringan Indomaret, demikian juga untuk "Sari Rasa" sudah mulai dipasarkan di $\mathrm{H}$ ypermart Jogja C ity M all. Dari pengembangan usaha tersebut, kedua mitra semakin percaya diri untuk melakukan pemasaran ke mancanegara.

\section{SIMPULAN}

D ari kegiatan yangtelah dilaksanakan tersebut dapat disimpulkan bahwa pemahaman terhadap pemasaran kepada wisatawan mancanegara bagi pengusahaU KM snack memang perlu ditingkatkan. Hasil dari pelatihan tersebut dapat membuka cakrawala berpikir mereka bahwa di Indonesia ini khususnya di Yogyakarta pasar wisatawan mancanegara sangat potensial. Demikian juga dengan menggunakan kemasan bahasa Inggris serta diperkuat oleh brosur dan website berbahasa Inggris semakin memantapkan dalam melakukan promosi.

Saran untuk kegiatan selanjutnya perlu didukung dengan adanya difersifikasi jenis produk dan disesuaikan dengan taste wisatawan mancanegara.

\section{UCAPAN TERIMA KASIH}

Semua kegiatan yang tercantum dalam program pengabdian masyarakat ini dapat terlaksana dengan sukses karena bantuan dari pihak-pihak sebagai berikut:

1. DRPM Kemen ristekdikti, yang telah menyediakan pendanaan untuk terlaksananya semua kegiatan yang telah diprogramkan.

2. LP3M UMY yang telah memberikan fasilitas dalam penyusunan proposal hingga sampai unggah proposal.

3. Jurusan IImu Komunikasi UMY yang telah memberikan fasilitas untuk pelatihan maupun magang para mitra dalam membuat berbagai desain promosi.

4. Kedua mitra yang telah bersedia untuk berkolaborasi dalam program pengabdian masyarakat ini.

\section{DAFTAR PUSTAKA}

Anandya, Dudi, 2005, Riset Pemasaran, Prospektif dan Terapan, Yogyakart: Bayumedia.

Pitana, I Gde dan I Ketut Surya Diarta, 2009, Pengantar IImu Pariwisata, Yogyakarta: Penerbit Andi.

Sunaryo, Bambang, 2013, Kebijakan Pembangunan Destinasi Pariwisata, Konsep dan Aplikasinya di Indonesia, Yogyakarta: Gava Media.
Susanta, Gatut dan M. Azrin Syamsudin, 2009, Cara Mudah Mendirikan dan Mengelola UMKM, Jakarta: Raih Asa Sukses.

Tjiptono, Fandy, 2008, Total Quality Service, Yogyakarta: Penerbit Andi. 